\title{
Enhancement in magnetic torque of cylindrical micro rotor by usage of directly consolidated $\alpha-\mathrm{Fe} / \mathrm{Pr}_{2} \mathrm{Fe}_{14} \mathrm{~B}$-based nanocomposite thick-films
}

\author{
F. Yamashita, ${ }^{1, a)}$ S. Nishimura, ${ }^{1}$ O. Kobayashi, ${ }^{1}$ M. Itoh, ${ }^{2}$ M. Nakano, ${ }^{3}$ H. Fukunaga, ${ }^{3}$ \\ and K. Ishiyama ${ }^{4}$ \\ ${ }^{1}$ Rotary Component Tech., Div., Minebea Co., Ltd., 1743-1 Asana, Fukuroi, Shizuoka 437-1193, Japan \\ ${ }^{2}$ Center for Advanced Science and Innovation, Osaka Univ., 2-1 Yamada-oka, Suita, Osaka 565-0871, Japan \\ ${ }^{3}$ Faculty of Engineering, Nagasaki Univ., 1-14 Bunkyo-machi, Nagasaki, 852-8521, Japan \\ ${ }^{4}$ Research Institute of Electrical Communication, Tohoku Univ., 2-1-1Katahira, Aoba, Sendai 980-8577, Japan
}

(Presented 17 November 2010; received 24 September 2010; accepted 11 November 2010; published online 24 March 2011)

\begin{abstract}
An advanced preparation method was carried out to obtain a magnetized cylindrical micro rotor fabricated from directly consolidated isotropic $\alpha-\mathrm{Fe} / \mathrm{Pr}_{2} \mathrm{Fe}_{14} \mathrm{~B}$ nanocomposite thick-films with self-bonding layer. A magnetic torque of the above film with the remanence value of $0.97 \mathrm{~T}$, the coercivity value of $650 \mathrm{kA} / \mathrm{m}$, and the $(\mathrm{BH})_{\max }$ value of $142 \mathrm{~kJ} / \mathrm{m}^{3}$ was investigated under different field strengths. Namely, magnetic torque of the above-mentioned rotor with a single pole pair increased by $117 \%$, compared with that of $\mathrm{Fe}_{3} \mathrm{~B} / \mathrm{Nd}_{2} \mathrm{Fe}_{14} \mathrm{~B}$ films with the remanence value of $1.1 \mathrm{~T}$, the coercivity value of $334 \mathrm{kA} / \mathrm{m}$, and the $(\mathrm{BH})_{\max }$ value of $95 \mathrm{~kJ} / \mathrm{m}^{3}$. It was found that the use of $\alpha-\mathrm{Fe} / \mathrm{Pr}_{2} \mathrm{Fe}_{14} \mathrm{~B}$ films is effective in obtaining a multipolarly magnetized micro rotor with highly dense torque as well as magnetic stability. (c) 2011 American Institute of Physics. [doi:10.1063/1.3553934]
\end{abstract}

\section{INTRODUCTION}

A micro cylindrical magnets rotor with high permeance coefficient and efficient magnetic properties is required for the highly dense torque in a micro motor for practicable applications. ${ }^{1}$ Recently, isotropic $\mathrm{Fe}_{3} \mathrm{~B} / \mathrm{R}_{2} \mathrm{Fe}_{14} \mathrm{~B}$ micro cylindrical magnets such as $1.5 \mathrm{~mm}$ or less in outer diameter were fabricated by melt-injecting into a copper mold. ${ }^{2}$ The obtained magnetic properties, however, were lower than that of melt-spinning method, that the remanence value of less than $0.66 \mathrm{~T}$ and the $(\mathrm{BH})_{\max }$ value of less than $69 \mathrm{~kJ} /$ $\mathrm{m}^{3}$, respectively. We have already estimated that the magnetic torque of a laminated isotropic $\mathrm{Fe}_{3} \mathrm{~B} / \mathrm{R}_{2} \mathrm{Fe}_{14} \mathrm{~B}$ film prepared from melt-spinning method with double pole pairs is much larger than that of an anisotropic bulk magnet with a single pole pair. ${ }^{3}$ We also have developed a small bonded magnet rotor with a relative density of $80 \%$ prepared from isotropic $\alpha-\mathrm{Fe} / \mathrm{Pr}_{2} \mathrm{Fe}_{14} \mathrm{~B}$ flakes. It was found that the magnet torque of a small motor using the bonded magnet increased by $114 \%$ compared with that of an conventional magnet rotor prepared from $\mathrm{Nd}_{2} \mathrm{Fe}_{14} \mathrm{~B}$ flakes. ${ }^{4,5}$

In this contribution, $\alpha-\mathrm{Fe} / \mathrm{Pr}_{2} \mathrm{Fe}_{14} \mathrm{~B}$ and $\mathrm{Fe}_{3} \mathrm{~B} / \mathrm{Nd}_{2} \mathrm{Fe}_{14} \mathrm{~B}$ nanocomposite films, respectively, were prepared from meltspinning method and an investigation on the magnetic torque of each film was evaluated after pulsed magnetization of 4 $\mathrm{MA} / \mathrm{m}$ to the in-plane direction. It was clarified that an enhancement in the magnetic torque of an $\alpha-\mathrm{Fe}_{2} / \mathrm{Pr}_{2} \mathrm{Fe}_{14} \mathrm{~B}$ film with a single pole pair exceeds $117 \%$ compared to that of a $\mathrm{Fe}_{3} \mathrm{~B} / \mathrm{Nd}_{2} \mathrm{Fe}_{14} \mathrm{~B}$ one. We found that an $\alpha-\mathrm{Fe} / \mathrm{Pr}_{2} \mathrm{Fe}_{14} \mathrm{~B}$ nanocomposite film is suitable for highly dense magnetic torque and also magnetic stability.

\footnotetext{
a) Author to whom correspondence should be addressed. Electronic mail: fmtsymst@minebea.co.jp.
}

\section{EXPERIMENTAL PROCEDURES}

In this section, the detailed preparation processes of two kinds of nanocrystalline films, a directly consolidated film and a bonded magnet, respectively, were described (see Fig. 1).

$\mathrm{Pr}_{9} \mathrm{Fe}_{73} \mathrm{Co}_{9} \mathrm{~B}_{7} \mathrm{Nb}_{1} \mathrm{~V}_{1}$ and $\mathrm{Nd}_{4.5} \mathrm{Fe}_{70} \mathrm{Co}_{5} \mathrm{~B}_{18.5} \mathrm{Cr}_{2}$ molten alloys, respectively, were melt spun into an as-cast ribbon with approximately 30 and $45 \mu \mathrm{m}$ in thickness and $2 \mathrm{~mm}$ in average width using a $\mathrm{Cu}$ wheel with an outer-diameter of $200 \mathrm{~mm}$ in Ar atmosphere at the pressure of $50 \mathrm{kPa}$. In the melt-spinning process, the ejection pressure of $5 \mathrm{kPa}$ by $\mathrm{Ar}$ gas, the orifice of $0.7 \mathrm{~mm}$ in the quartz crucible, and the wheel speed of $30 \mathrm{~m} / \mathrm{s}$, respectively, were used. The as-cast ribbons were cut to $50 \mathrm{~mm}$ or less in length and crystallized at the elevated temperature of 650 and $680{ }^{\circ} \mathrm{C}$ for 0 and 10

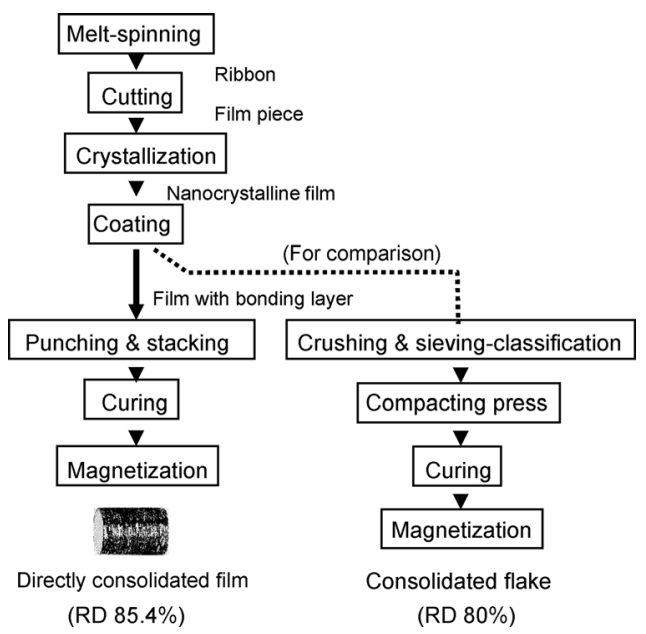

FIG. 1. Processes for producing a directly consolidated film prepared from isotropic nanocomposite melt-spun ribbons with self-bonding layer together with consolidated flake for comparison. 


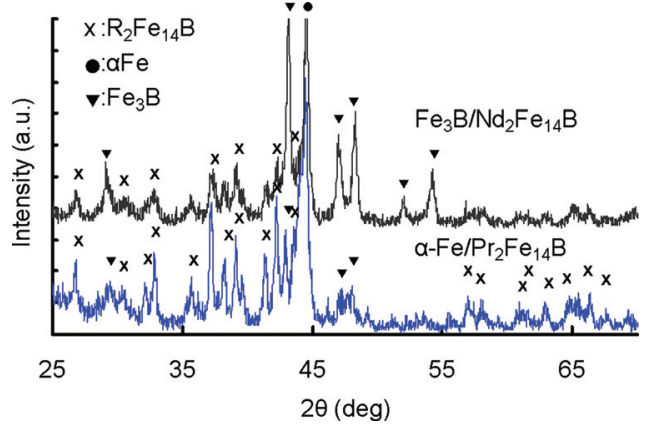

FIG. 2. (Color online) X-ray diffraction patterns of $\mathrm{Nb}-\mathrm{V}-\mathrm{Co}-$ doped $\alpha$-Fe/ $\mathrm{Pr}_{2} \mathrm{Fe}_{14} \mathrm{~B}$ and $\mathrm{Cr}$-Co-doped $\mathrm{Fe}_{3} \mathrm{~B} / \mathrm{Nd}_{2} \mathrm{Fe}_{14} \mathrm{~B}$-based ribbons after heat-treatment.

min with heating rate of 300 and $200{ }^{\circ} \mathrm{C} / \mathrm{min}$, respectively. After cooling them to room temperature, $\mathrm{Nb}-\mathrm{V}-\mathrm{Co}$-doped $\alpha$ $\mathrm{Fe} / \mathrm{Pr}_{2} \mathrm{Fe}_{14} \mathrm{~B}$ films and $\mathrm{Cr}$-Co-doped $\mathrm{Fe}_{3} \mathrm{~B} / \mathrm{Nd}_{2} \mathrm{Fe}_{14} \mathrm{~B}$ ones were coated with approximately 5 - $\mu \mathrm{m}$-thick or less selfbonding layers.

Each film was pierced into a disk shape under a pressure up to $50 \mathrm{kN}$. The intended dimensions are $1.6 \mathrm{~mm}$ in outer diameter. In addition, the directly consolidated film was prepared into several specific lengths such as approximately $0.5-2.0$ in $\mathrm{L} / \mathrm{D}$ ratio (L: length, $\mathrm{D}$ : diameter) in the punching. Namely, the directly consolidated film was solidified under a pressure of $50 \mathrm{MPa}$ at the temperature of $180{ }^{\circ} \mathrm{C}$ for $5 \mathrm{~min}$. A rigid consolidated film obtained through the cross-linking was magnetized to an in-plane direction under the pulsed magnetic field of $4 \mathrm{MA} / \mathrm{m}$.

We also prepared a consolidated flake (bonded magnets) by using the above-mentioned film. The particle size of the compound was adjusted to $350 \mu \mathrm{m}$ or less by crushing and sieving-classification. The obtained compound was compacted into a specific shape with $1.6 \mathrm{~mm}$ in outer diameter under a pressure of $1 \mathrm{GPa}$ at $180^{\circ} \mathrm{C}$. Through the compaction, a rigid sample for comparison could be obtained by cured of self-bonding material.

\section{RESULTS AND DISCUSSION}

An investigation on x-ray diffraction pattern, magnetic properties, and magnetic torque was carried out. Each magnetic torque in rotating field range from 4 to $400 \mathrm{kA} / \mathrm{m}$ was measured with a magnetic torque meter.

The amorphous state of as-spun ribbons as a homogeneous precursor is important for crystallographically coherent

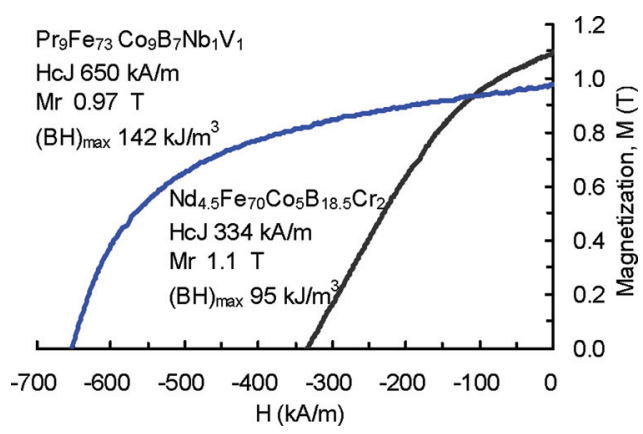

FIG. 3. (Color online) Demagnetization curves of Nb-V-Co-doped $\alpha-\mathrm{Fe} /$ $\mathrm{Pr}_{2} \mathrm{Fe}_{14} \mathrm{~B}$ and $\mathrm{Cr}$-Co-doped $\mathrm{Fe}_{3} \mathrm{~B} / \mathrm{Nd}_{2} \mathrm{Fe}_{14} \mathrm{~B}$-based film prepared from meltspinning method.

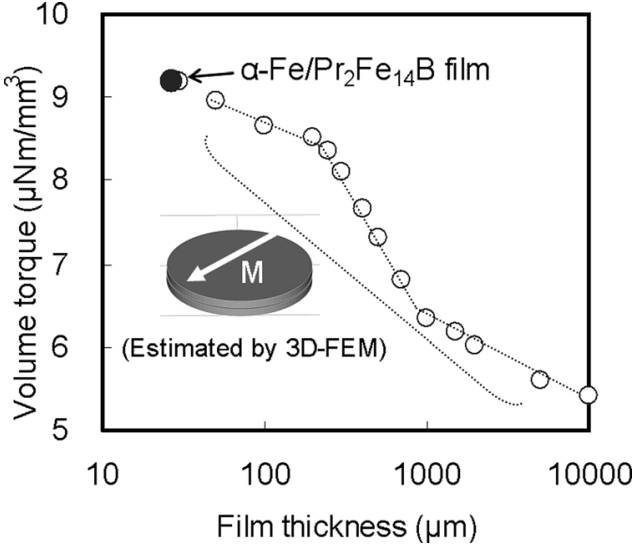

FIG. 4. Volume magnetic torque of magnetized $\alpha-\mathrm{Fe} / \mathrm{Pr}_{2} \mathrm{Fe}_{14} \mathrm{~B}$-based sample with single pole pair and their dependency on the film thickness calculated by a 3D finite element model.

formation of nanocrystalline hard magnetic phases and soft magnetic phases simultaneously, which insures a strong exchange coupling between the two phases. ${ }^{6}$ In the experiment, we confirmed that an $\alpha-\mathrm{Fe} / \operatorname{Pr}_{2} \mathrm{Fe}_{14} \mathrm{~B}$ film and also a $\mathrm{Fe}_{3} \mathrm{~B} / \mathrm{Nd}_{2} \mathrm{Fe}_{14} \mathrm{~B}$ one consists of $\mathrm{Fe}_{3} \mathrm{~B}, \mathrm{R}_{2} \mathrm{Fe}_{14} \mathrm{~B}$ and $\alpha$-Fe phases as seen in Fig. 2. We, further, prepared film specimens with approximately $2 \mathrm{~mm}^{2}$ in order to evaluate magnetic properties to an in-plane direction by using a VSM after pulse-magnetization at $4 \mathrm{MA} / \mathrm{m}$, and we confirmed that they had typical magnetic properties of 0.97 and $1.1 \mathrm{~T}$ in remanence, 650 and $334 \mathrm{kA} / \mathrm{m}$ in coercivity, 142 and $95 \mathrm{~kJ} / \mathrm{m}^{3}$ in $(\mathrm{BH})_{\max }$, respectively, as seen in Fig. 3.

The magnetic torque of an obtained film was examined with a magnetic torque meter because the measured magnetic torque is more applicable than the evaluation on general S-T equipment in the magnetized cylindrical micro rotor with a single pole pair. According to the calculation by a 3D finite element model as seen in Fig. 4, assuming that the outer diameter of the magnetized film is constant, the volume magnetic torque with the thickness range of $10-300 \mu \mathrm{m}$ hardly changes; on the other hand, the volume magnetic one obviously decreases as film thickness exceeded $300 \mu \mathrm{m}$ or more. The above-mentioned reduction is considered to be attributed to a shape-magnetic-anisotropy deterioration of a film.

Figure 5 shows the volume magnetic torque of an $\alpha-\mathrm{Fe} /$ $\mathrm{Pr}_{2} \mathrm{Fe}_{14} \mathrm{~B}$ film with a single pole pair as a function of field strength compared with that of a $\mathrm{Fe}_{3} \mathrm{~B} / \mathrm{Nd}_{2} \mathrm{Fe}_{14} \mathrm{~B}$ one. As the field range was between 4 and $40 \mathrm{kA} / \mathrm{m}$, good linearity of a torque peak as well as same phases of the torque curves
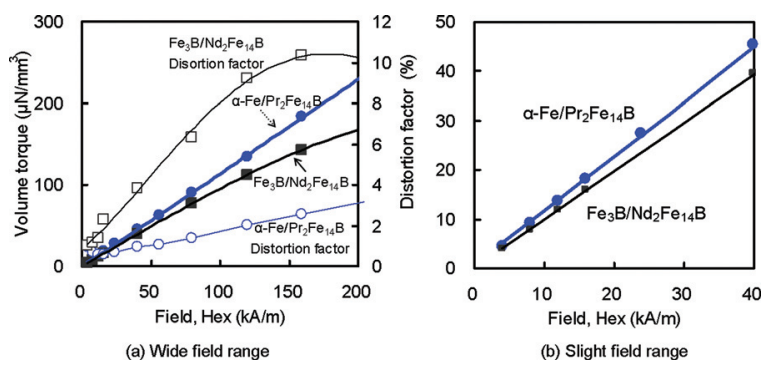

FIG. 5. (Color online) Volume magnetic torque and a distortion factor of torque curve of an $\alpha$-Fe/ $\operatorname{Pr}_{2} \mathrm{Fe}_{14} \mathrm{~B}$-based film with single pole pair as a function of field strength compared with that for a $\mathrm{Fe}_{3} \mathrm{~B} / \mathrm{Nd}_{2} \mathrm{Fe}_{14} \mathrm{~B}$ one. 


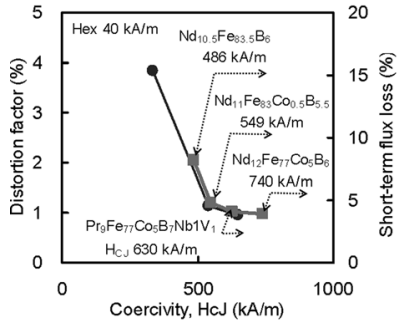

(a)

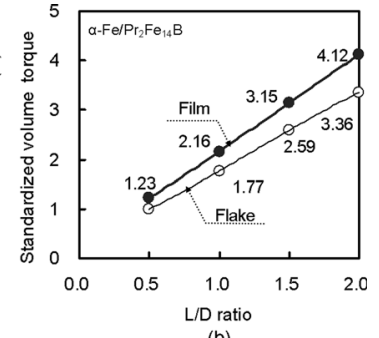

(b)
FIG. 6. Distortion factor of the magnetic torque curve of obtained films and short-term flux loss as a function of coercivity (a), standardized volume magnetic torque of the directly consolidated film as a function of $\mathrm{L} / \mathrm{D}$ ratio together with those of flake for comparison (b). The rotating field was $8 \mathrm{kA} / \mathrm{m}$.

could be observed. In the above field at $8 \mathrm{kA} / \mathrm{m}$, the volume magnetic torque of an $\alpha-\mathrm{Fe} / \operatorname{Pr}_{2} \mathrm{Fe}_{14} \mathrm{~B}$ film was $9.2 \mu \mathrm{Nm} /$ $\mathrm{mm}^{3}$, which was $117 \%$ larger than that of a $\mathrm{Fe}_{3} \mathrm{~B} / \mathrm{Nd}_{2} \mathrm{Fe}_{14} \mathrm{~B}$ one. Although a distortion factor of the magnetic torque curve deteriorated remarkably at a strong magnetic field higher than $80 \mathrm{kA} / \mathrm{m}$, an $\alpha-\mathrm{Fe} / \mathrm{Pr}_{2} \mathrm{Fe}_{14} \mathrm{~B}$ film was relatively smaller deterioration than that of a $\mathrm{Fe}_{3} \mathrm{~B} / \mathrm{Nd}_{2} \mathrm{Fe}_{14} \mathrm{~B}$ one. It is generally said that the effect of the short-term flux loss, which is attributed to irreversible magnetization reversal at an exposed temperature, is more important than that of the long-term flux loss in magnet torque of cylindrical magnetized micro rotor. In the systematic evaluation on the flux loss in nanocomposite bonded magnets with the various coercivity values, we have already found that short-term as well as long-term flux losses in several nanocomposite bonded magnets were smaller than that of a conventional isotropic $\mathrm{Nd}_{2} \mathrm{Fe}_{14} \mathrm{~B}$ bonded magnet despite their small coercivity values. ${ }^{4}$ The relationship between distortion factor and short-term flux loss, therefore, was investigated in the study. Figure 6(a) shows the relationship between the distortion factor of magnetic torque curves and short-term flux loss as a function of coercivity values. Here, the short-term flux loss values of three consolidated nanocomposite flakes such as $\mathrm{Nd}_{10.5} \mathrm{Fe}_{83.5} \mathrm{~B}_{6}$ were also displayed. ${ }^{4}$ The dependency of distortion factor of each film together with short-term flux losses of consolidated flakes on coercivity values showed the same tendency, and both the vertical values drastically increased at coercivity value lower than approximately 600 $\mathrm{kA} / \mathrm{m}$. These results suggest that the distortion factor of the magnetic torque curve of each magnetized sample is attributed to a magnetization reversal. Resultantly, an $\alpha-\mathrm{Fe} /$ $\mathrm{Pr}_{2} \mathrm{Fe}_{14} \mathrm{~B}$ film with a highly dense magnet torque as well as a satisfactory magnetic stability for micro cylindrical magnet rotor application could be prepared.

Preparation of a directly consolidated film enabled us to achieve an enhancement in the magnetic torque on the shape magnetic anisotropy and increase relative density compared with that of a consolidated flake with same dimension and alloy composition. Table I shows a typical relative density, a volume magnetic torque, and a $\mathrm{dT} / \mathrm{dH}$-gradient of directly consolidated films and flakes. We, further, calculated the volume magnetic torque for different $\mathrm{L} / \mathrm{D}$ ratios by using a $3 \mathrm{D}$ finite element model. Figure 6(b) shows the volume magnetic torque of the directly consolidated film as a function of $\mathrm{L} / \mathrm{D}$ ratio together with those of a consolidated flake for com-
TABLE I. Typical relative density, volume magnetic torque, and $\mathrm{dT} / \mathrm{dH}-$ gradient of $\alpha$-Fe/ $\mathrm{Pr}_{2} \mathrm{Fe}_{14} \mathrm{~B}$-based directly consolidated films and flakes.

\begin{tabular}{lcccccc}
\hline \hline Material & RD & \multicolumn{4}{c}{ Volume magnetic torque $\left(\mu \mathrm{Nm} / \mathrm{mm}^{3}\right)$} & \\
\cline { 3 - 6 } form & $(\%)$ & $4 \mathrm{kA} / \mathrm{m}$ & $8 \mathrm{kA} / \mathrm{m}$ & $12 \mathrm{kA} / \mathrm{m}$ & $16 \mathrm{kA} / \mathrm{m}$ & $\begin{array}{c}\mathrm{dT} / \mathrm{dH} \\
\text { gradient }\end{array}$ \\
\hline Film & 85.4 & 4.62 & 9.18 & 13.71 & 18.26 & 1.15 \\
Flake & 80.0 & 3.76 & 7.46 & 11.21 & 14.92 & 0.94 \\
\hline \hline
\end{tabular}

parison. In the case of a single pole pair magnetization to inplane direction in the sample, an enhancement in a volume magnetic torque is considered to be attributed to the in-plane shape-magnetic-anisotropy compared with that of a consolidated flake with the same materials and dimensions. Furthermore, the values of $\mathrm{dT} / \mathrm{dH}$-gradient at field range of 4-16 $\mathrm{kA} / \mathrm{m}$ for the directly consolidated film $(\mathrm{L} / \mathrm{D}=0.5)$ could be improved by $123 \%$ compared with that of a consolidated flake. We also considered that the above $\mathrm{dT} / \mathrm{dH}$-gradient is corresponding to a torque constant of a micro DC brushless motor. In particular, as their L/D ratio increases, the above superior magnetic torque and $\mathrm{dT} / \mathrm{dH}$-gradient of the directly consolidated film by using the shape-magnetic-anisotropy were clearly confirmed. These results indicate that effective utilization of isotropic film magnets with an increase in remanence and a decrease in magnetization reversal are indispensable to develop miniaturized devices.

Consequently, we found that the usage of a directly consolidated isotropic film magnet with self-bonding layer is expected to be suitable to a multipolarly magnetized micro rotor with a highly dense torque even if their outer diameter became approximately $1.6 \mathrm{~mm}$ or less.

\section{CONCLUSION}

In this study, we succeeded in a highly dense torque as well as magnetic stability by taking advantage of a shapemagnetic-anisotropy due to an optimized material form and $\mathrm{L} / \mathrm{D}$ ratio through the preparation of a directly consolidated film with approximately $1.6 \mathrm{~mm}$ in outer diameter comprising isotropic $\alpha$-Fe/ $\operatorname{Pr}_{2} \mathrm{Fe}_{14} \mathrm{~B}$ nanocomposite thick-films with self-bonding layer.

\section{ACKNOWLEDGMENTS}

This work was supported from New Energy and Industrial Technology Development Organization (NEDO, Project P07026) of Japan.

${ }^{1}$ F. Yamashita, in 142th Topical Symposium of the Magnetics Society of Japan (2005) p. 18.

${ }^{2}$ H. W. Chang, C. C. Hsieh, J. Y. Gan, Y. T. Cheng, M. F. Shih, and W. C. Chang, in Proceedings of the 21th International Workshop on Rare-Earth Magnets and Their Applications, Published by the Jožef Stefan Institute, Bled, Slovenia, (2010), p. 109.

${ }^{3}$ F. Yamashita, S. Nishimura, N. Menjo, O. Kobayashi, M. Nakano, H. Fukunaga, and K. Ishiyama, IEEE Trans. Magn. 46(6), 2012 (2010).

${ }^{4}$ F. Yamashita, Y. Sasaki, and H. Fukunaga, J. Magn. Soc. Japan 25, 683 (2001). ${ }^{5}$ H. Yamamoto, K. Takasugi, and F. Yamashita, in Proceedings of the 17th International Workshop on Rare-Earth Magnets and Their Applications, Published by the Rinton Press, Newark, Delaware, USA (2002), p. 307.

${ }^{6}$ J. H. Park, D. H. Lee, and T. Jang, J. Ceram. Proc. Res. 3(2), 57 (2002). 